\title{
Beneficial effects of intercellular interactions between pancreatic islet cells in blood glucose regulation
}

\author{
Junghyo Jo \\ Laboratory of Biological Modeling, \\ National Institute of Diabetes and Digestive and Kidney Diseases, \\ National Institutes of Health, Bethesda, MD 20892, U.S.A. \\ Moo Young Choi ${ }^{1}$ \\ Department of Physics and Astronomy and Center for Theoretical Physics, \\ Seoul National University, Seoul 151-747, Korea \\ Duk-Su Koh \\ Department of Physiology and Biophysics, \\ University of Washington, Seattle, WA 98195, U.S.A.
}

October 25, 2018 
${ }^{1}$ Corresponding author. Address: Department of Physics and Astronomy, Seoul National University, Seoul 151-747, Korea. E-mail: mychoi@snu.ac.kr 


\begin{abstract}
Glucose homeostasis is controlled by the islets of Langerhans which are equipped with $\alpha$-cells increasing the blood glucose level, $\beta$-cells decreasing it, and $\delta$-cells the precise role of which still needs identifying. Although intercellular communications between these endocrine cells have recently been observed, their roles in glucose homeostasis have not been clearly understood. In this study, we construct a mathematical model for an islet consisting of two-state $\alpha-, \beta$-, and $\delta$-cells, and analyze effects of known chemical interactions between them with emphasis on the combined effects of those interactions. In particular, such features as paracrine signals of neighboring cells and cell-to-cell variations in response to external glucose concentrations as well as glucose dynamics, depending on insulin and glucagon hormone, are considered explicitly. Our model predicts three possible benefits of the cell-to-cell interactions: First, the asymmetric interaction between $\alpha$ - and $\beta$-cells contributes to the dynamic stability while the perturbed glucose level recovers to the normal level. Second, the inhibitory interactions of $\delta$-cells for glucagon and insulin secretion prevent the wasteful co-secretion of them at the normal glucose level. Finally, the glucose dose-responses of insulin secretion is modified to become more pronounced at high glucose levels due to the inhibition by $\delta$-cells. It is thus concluded that the intercellular communications in islets of Langerhans should contribute to the effective control of glucose homeostasis.
\end{abstract}

Key words: glucose homeostasis, islets of Langerhans, feedback, diabetes 


\section{Introduction}

Homeostasis, maintenance of the constant physiological state, is one of the main characteristics of life. In particular, glucose homeostasis is critical because glucose is the energy source for our bodies; the malfunctioning of this process causes several disease states including diabetes mellitus and brain coma.

In order to understand glucose homeostasis, we first need to examine the tissue controlling the blood glucose level, the islet of Langerhans in the pancreas. It consists mainly of three types of endocrine cells: $\alpha$-cells which secrete glucagon hormone increasing the glucose level, $\beta$-cells which secrete insulin decreasing the glucose level, and $\delta$-cells which secrete somatostatin, known to inhibit activities of $\alpha$ - and $\beta$-cells. The hormone secretion of a cell influences the behavior of neighboring cells, and is thus tightly correlated with the islet structure (Hopcroft et al., 1985; Pipeleers et al., 1982). In rodents, an islet contains about 1,000 endocrine cells on average: $\beta$-cells, occupying the most volume (70 to $80 \%$ ) of an islet, populate largely in its core, whereas non- $\beta$-cells are located on the mantle (Brissova et al., 2005).

To the first approximation, $\alpha$ - and $\beta$-cells should be sufficient for glucose control because $\alpha$-cells can increase the glucose level whereas $\beta$-cells can decrease the level. The importance of this bi-hormonal mechanism for glucose homeostasis has been well recognized (Cherrington et al., 1976). However, it should be noted that endocrine cells in the islet interact with each other rather than act independently. For example, the electrical coupling between $\beta$-cells through gap-junctions is known to enhance insulin secretion of cou- 
pled $\beta$-cells (Jo et al., 2005; Pipeleers et al., 1982; Sherman et al., 1988). In addition, it has been recently reported that chemical interactions between neighboring cells through hormones (Cherrington et al., 1976; Franklin et al., 2005;

Orci \& Unger, 1975; Ravier \& Rutter, 2005; Samols et al., 1965; Samols \& Harrison, 1976 Soria et al., 2000) and neurotransmitters (Brice et al., 2002, Franklin \& Wollheim, 2004, Gilon et al., 1991; Moriyama \& Hayashi, 2003; Rorsman et al., 1989; Wendt et al., 2004), termed "paracrine interaction," affect glucose regulation.

Among these intercellular communications, enhancement of insulin secretion by glucagon (Brereton et al., 2007; Samols et al., 1965; Soria et al., 2000) seems to be paradoxical because $\alpha$-cells, playing the reciprocal role to $\beta$-cells in glucose regulation, promote the activity of $\beta$-cells. In contrast, insulin, secreted by $\beta$-cells, inhibits glucagon secretion of $\alpha$-cells (Cherrington et al., 1976; Franklin et al., 2005; Ravier \& Rutter, 2005: Samols \& Harrison, 1976 ; Soria et al., 2000), which appears natural. Furthermore, the role of the third cell-type, $\delta$ cells, is still not completely known although there have been reports that somatostatin hormone, secreted by $\delta$-cells, suppresses the hormone secretion of both $\alpha$ - and $\beta$-cells (Cherrington et al., 1976; Daunt et al., 2006; Orci \& Unger, 1975; Soria et al., 2000).

What is then the raison d'etre of the paradoxical interactions between $\alpha$ - and $\beta$-cells and the inhibitory action by $\delta$-cells? Despite previous studies as to these questions over the last thirty years Orci \& Unger, 1975, Pipeleers, 1987; Soria et al., 2000; Unger \& Orci, 1977), there still lacks concrete understanding of the role of these interactions in terms of glucose homeostasis. The primary difficulty in understanding these interactions lies in the complexity of the islet system which includes many interactions be- 
tween different coexisting cell-types working in different conditions.

In this paper, we analyze the interactions between $\alpha-, \beta$-, and $\delta$-cells, which contribute to the precise control of the glucose level, by means of a mathematical model incorporating experimentally known interactions between islet cells (see above). As a result, our model predicts that the intracellular interactions modify insulin and glucagon secretion in a way to control the blood glucose level more efficiently.

\section{$2 \quad$ Islet model}

\subsection{Activity of islet cells}

We begin with a simplified model in which cells of each type can take one of two states (active and silent). The state of a cell, represented by "Ising spin" $\sigma$, is defined to be active $(\sigma=+1)$ when the cell secretes islet hormone; otherwise the state is defined as silent $(\sigma=-1)$. Accordingly, the state of an islet consisting of $\alpha$-, $\beta$-, and $\delta$-cells can be represented by $\left(\sigma_{\alpha}, \sigma_{\beta}, \sigma_{\delta}\right)$. There is a total of $2^{3}$ possible states of the islet, among which $(+1,-1,-1)$ and $(-1,+1,+1)$ describe the islet state at low and high glucose levels, respectively. The main source of changing cell states is the blood glucose level $\tilde{G}$, which globally influences all cells. In addition, the paracrine interaction $\tilde{J}$ from neighboring cells locally affects cell states. In this manner we obtain a simple Ising-type model, generally characterizing two-state dynamics in statistical physics: The glucose level $\tilde{G}$ corresponds to the external magnetic field and the paracrine interaction $\tilde{J}$ to the local interaction between spins. 
¿From the known cellular interactions illustrated in Fig. 1, one may determine local stimuli $G_{\alpha}, G_{\beta}$, and $G_{\delta}$, which change the states of $\alpha^{-}, \beta-$, and $\delta$-cells, respectively, in the forms:

$$
\begin{aligned}
G_{\alpha} & =-G-\frac{1+\sigma_{\beta}}{2} J_{\alpha \beta}-\frac{1+\sigma_{\delta}}{2} J_{\alpha \delta} \\
G_{\beta} & =G+\frac{1+\sigma_{\alpha}}{2} J_{\beta \alpha}-\frac{1+\sigma_{\delta}}{2} J_{\beta \delta} \\
G_{\delta} & =m G,
\end{aligned}
$$

where $G \equiv \tilde{G}-\tilde{G}_{0}$ measures the excess glucose level from the basal glucose level $\tilde{G}_{0}$ during the fasting period. The reciprocal nature of $\alpha$ - and $\beta$-cells in the responses to glucose is manifested by the opposite signs in front of $G$ in the first equation (for $G_{\alpha}$ ) and the second one (for $G_{\beta}$ ) of Eq. 1. In addition, the asymmetric interaction between these two cell types is also reflected in the second terms involving $J_{\alpha \beta}$ and $J_{\beta \alpha}$ of the equations. For simplicity, we assume that the interaction strength $J_{\beta \alpha}$ from $\alpha$ - to $\beta$-cells is the same as $J_{\alpha \beta}$ from $\beta$ - to $\alpha$-cells and given by $J_{1}$, i.e., $J_{\alpha \beta}=J_{\beta \alpha}=J_{1}$. The last terms involving $J_{\alpha \delta}$ and $J_{\beta \delta}$ describe the inhibition effects of $\delta$ cells on $\alpha$ - and $\beta$-cells, both with negative signs. Although the endogenous strengths of the interactions from $\delta$-cells to $\alpha$ - and $\beta$-cells are not known, the exogenous stimulus of somatostatin has been reported to inhibit both insulin and glucagon secretion to a similar degree (Cherrington et al., 1976). As a first approximation, it is thus assumed that both interactions have the same strength: $J_{\alpha \delta}=J_{\beta \delta}=J_{2}$. Here the interaction strengths $J_{1}$ and $J_{2}$ are expressed in terms of the relative effects to glucose stimulation, and therefore have the unit of $\mathrm{mM}$ corresponding to the hormonal stimulus $\tilde{J}$, 
namely, a given amount of stimulus $\tilde{J}$ by hormone is considered to produce the same effects on a cell as a certain amount $J$ of glucose stimulation. In our simplified model, $\delta$-cells are not influenced by neighboring $\alpha$ - and $\beta$-cells but stimulated solely by glucose; therefore, $G_{\delta}$ depends only on $G$ in Eq. 1, Like $\beta$-cells, $\delta$-cells become active, and secrete somatostatin above a threshold level of glucose. The glucose sensitivity of $\delta$-cells is expected to have a value between zero and unity, i.e., $0<m<1$ because the threshold level for the activation of $\delta$-cells is lower than that of $\beta$-cells (Efendić et al., 1979, Nadal et al., 1999). We thus choose the value $m=0.5$ in this study; the overall behavior does not depend qualitatively on the value of $m$.

For given local stimulus $G_{\alpha}$ considering glucose stimulus $G$ and effects of insulin and somatostatin, the transition rate of an $\alpha$-cell from state $\sigma_{\alpha}$ to state $-\sigma_{\alpha}$ depends on the states of other cell types as well as its own state, and is denoted as $w_{\alpha}\left(\sigma_{\alpha}, \sigma_{\beta}, \sigma_{\delta}\right)$. This transition rate should satisfy the detailed balance condition between two $\alpha$-cell states $\sigma_{\alpha}$ and $-\sigma_{\alpha}$ at equilibrium:

$$
w_{\alpha}\left(\sigma_{\alpha}, \sigma_{\beta}, \sigma_{\delta}\right) P\left(\sigma_{\alpha}\right)=w_{\alpha}\left(-\sigma_{\alpha}, \sigma_{\beta}, \sigma_{\delta}\right) P\left(-\sigma_{\alpha}\right),
$$

where the probability $P\left(\sigma_{\alpha}\right)$ for state $\sigma_{\alpha}$ follows the Boltzmann distribution $\exp \left[-G_{\alpha}\left(1+\sigma_{\alpha}\right) / 2 \Theta\right]$ with respect to the quantity $G_{\alpha}\left(1+\sigma_{\alpha}\right) / 2$ for the local stimulus $G_{\alpha}$. Namely, $\alpha$-cells favor the state minimizing the quantity $G_{\alpha}\left(1+\sigma_{\alpha}\right) / 2$. Here $\Theta$ measures the amount of uncertainty, which is inevitable in biological systems. The origin may be the heterogeneous glucose sensitivity of cells and/or the environmental noise including thermal fluc- 
tuations. It is obvious that $G_{\alpha}\left(1+\sigma_{\alpha}\right) / 2$ and $\Theta$ correspond to the energy and the temperature, respectively, in statistical physics. In this study, the "temperature" is taken to be unity $(\Theta=1)$ in units of the "energy", which is biologically tantamount to the fluctuations caused by $1 \mathrm{mM}$ change of glucose stimulation.

The ratio between the reciprocal transition rates thus reads

$$
\begin{aligned}
\frac{w_{\alpha}\left(\sigma_{\alpha}, \sigma_{\beta}, \sigma_{\delta}\right)}{w_{\alpha}\left(-\sigma_{\alpha}, \sigma_{\beta}, \sigma_{\delta}\right)} & =\exp \left[-\frac{1}{\Theta} G_{\alpha} \sigma_{\alpha}\right] \\
& =\exp \left[\frac{1}{\Theta}\left(G_{\alpha}^{\mathrm{eff}} \sigma_{\alpha}+\frac{J_{1}}{2} \sigma_{\alpha} \sigma_{\beta}+\frac{J_{2}}{2} \sigma_{\delta} \sigma_{\alpha}\right)\right]
\end{aligned}
$$

with $G_{\alpha}^{\text {eff }} \equiv G+J_{1} / 2+J_{2} / 2$, where Eq. 1 has been used to obtain the second line. There the three stimulation terms represent effective glucose stimulation, paracrine interaction from $\beta$-cells, and another from $\delta$-cells, respectively. Assuming that these stimuli affect independently the $\alpha$-cell state, we write the transition rate in the form

$$
\begin{aligned}
w_{\alpha}= & \frac{1}{2 \tau}\left[1+\tanh \left(\frac{G_{\alpha}^{\mathrm{eff}}}{2 \Theta}\right) \sigma_{\alpha}\right]\left[1+\tanh \left(\frac{J_{1}}{4 \Theta}\right) \sigma_{\alpha} \sigma_{\beta}\right] \\
& \times\left[1+\tanh \left(\frac{J_{2}}{4 \Theta}\right) \sigma_{\delta} \sigma_{\alpha}\right]
\end{aligned}
$$

where $\tau$ measures the characteristic time of the transition and it has been noted that $\tanh (y \sigma)=\sigma \tanh y$ for $\sigma= \pm 1$. Note that among possible transition rates satisfying Eq. 2, we adopt the Glauber dynamics (Glauber, 1963) to choose the specific form of Eq. 4, which exhibits the sigmoidal form ubiquitously describing response functions in biological systems. However, the 
behavior of the system in general does not depend qualitatively on the specific form of the transition rate satisfying Eq. 2, Similarly, we obtain the transition rates $w_{\beta}$ and $w_{\delta}$ of $\beta$ - and $\delta$-cells.

The transition rates of three cell types can be summarized as

$$
\begin{aligned}
w_{x}\left(\sigma_{\alpha}, \sigma_{\beta}, \sigma_{\delta}\right)= & \frac{1}{2 \tau}\left[w^{x}+w_{\alpha}^{x} \sigma_{\alpha}+w_{\beta}^{x} \sigma_{\beta}+w_{\delta}^{x} \sigma_{\delta}+w_{\alpha \beta}^{x} \sigma_{\alpha} \sigma_{\beta}\right. \\
& \left.+w_{\beta \delta}^{x} \sigma_{\beta} \sigma_{\delta}+w_{\delta \alpha}^{x} \sigma_{\delta} \sigma_{\alpha}+w_{\alpha \beta \delta}^{x} \sigma_{\alpha} \sigma_{\beta} \sigma_{\delta}\right]
\end{aligned}
$$

with $x=\alpha, \beta$, and $\delta$, where the coefficients are given in Tables 1 and 2 . The master equation, describing the evolution of the probability $P\left(\sigma_{\alpha}, \sigma_{\beta}, \sigma_{\delta}\right)$ for the islet in state $\left(\sigma_{\alpha}, \sigma_{\beta}, \sigma_{\delta}\right)$, reads

$$
\begin{aligned}
\frac{d}{d t} P & \left(\sigma_{\alpha}, \sigma_{\beta}, \sigma_{\delta}\right) \\
= & w_{\alpha}\left(-\sigma_{\alpha}, \sigma_{\beta}, \sigma_{\delta}\right) P\left(-\sigma_{\alpha}, \sigma_{\beta}, \sigma_{\delta}\right)+w_{\beta}\left(\sigma_{\alpha},-\sigma_{\beta}, \sigma_{\delta}\right) P\left(\sigma_{\alpha},-\sigma_{\beta}, \sigma_{\delta}\right) \\
& +w_{\delta}\left(\sigma_{\alpha}, \sigma_{\beta},-\sigma_{\delta}\right) P\left(\sigma_{\alpha}, \sigma_{\beta},-\sigma_{\delta}\right)-w_{\alpha}\left(\sigma_{\alpha}, \sigma_{\beta}, \sigma_{\delta}\right) P\left(\sigma_{\alpha}, \sigma_{\beta}, \sigma_{\delta}\right) \\
& \quad-w_{\beta}\left(\sigma_{\alpha}, \sigma_{\beta}, \sigma_{\delta}\right) P\left(\sigma_{\alpha}, \sigma_{\beta}, \sigma_{\delta}\right)-w_{\delta}\left(\sigma_{\alpha}, \sigma_{\beta}, \sigma_{\delta}\right) P\left(\sigma_{\alpha}, \sigma_{\beta}, \sigma_{\delta}\right)
\end{aligned}
$$

with the transition rates $w_{\alpha}, w_{\beta}$, and $w_{\delta}$ in Eq. 5. Note that Eq. 6] describes the net flux to state $\left(\sigma_{\alpha}, \sigma_{\beta}, \sigma_{\delta}\right)$ simply given by the difference between the in-flux to state $\left(\sigma_{\alpha}, \sigma_{\beta}, \sigma_{\delta}\right)$ from other states $\left(-\sigma_{\alpha}, \sigma_{\beta}, \sigma_{\delta}\right),\left(\sigma_{\alpha},-\sigma_{\beta}, \sigma_{\delta}\right)$, and $\left(\sigma_{\alpha}, \sigma_{\beta},-\sigma_{\delta}\right)$ and the out-flux from state $\left(\sigma_{\alpha}, \sigma_{\beta}, \sigma_{\delta}\right)$ to others.

¿From this master equation, it is straightforward to obtain the time evolution of the ensemble averages of the cell states and their correlations. For example, multiplying both sides of Eq. 6] by $\sigma_{\alpha}$ and summing over all configurations, we obtain the evolution equation for the average $\left\langle\sigma_{\alpha}\right\rangle \equiv$ 
$\sum_{\sigma_{\alpha}, \sigma_{\beta}, \sigma_{\delta}} \sigma_{\alpha} P\left(\sigma_{\alpha}, \sigma_{\beta}, \sigma_{\delta}\right)$ of the state of $\alpha$-cells:

$$
\frac{d}{d t}\left\langle\sigma_{\alpha}\right\rangle=-2\left\langle\sigma_{\alpha} w_{\alpha}\left(\sigma_{\alpha}, \sigma_{\beta}, \sigma_{\delta}\right)\right\rangle
$$

and similarly,

$$
\begin{aligned}
\frac{d}{d t}\left\langle\sigma_{\beta}\right\rangle & =-2\left\langle\sigma_{\beta} w_{\beta}\left(\sigma_{\alpha}, \sigma_{\beta}, \sigma_{\delta}\right)\right\rangle \\
\frac{d}{d t}\left\langle\sigma_{\delta}\right\rangle & =-2\left\langle\sigma_{\delta} w_{\alpha}\left(\sigma_{\alpha}, \sigma_{\beta}, \sigma_{\delta}\right)\right\rangle .
\end{aligned}
$$

Note that $1+\left\langle\sigma_{\alpha}\right\rangle$ gives twice the average activity of $\alpha$-cells, etc.

Among the eight equations for the probability $P\left(\sigma_{\alpha}, \sigma_{\beta}, \sigma_{\delta}\right)$ corresponding to the eight possible states of the islet, only seven are independent, due to the normalization condition $\sum_{\sigma_{\alpha}, \sigma_{\beta}, \sigma_{\delta}} p\left(\sigma_{\alpha}, \sigma_{\beta}, \sigma_{\delta}\right)=1$. Therefore, there exist four more equations in addition to the above three describing the average of cell states. Those are evolution equations for correlations of two cell states and of three cell states. The equation for the correlation function $\left\langle\sigma_{\alpha} \sigma_{\beta}\right\rangle$ of the $\alpha$-cell and $\beta$-cell states can again be derived from Eq. 6, multiplied by $\sigma_{\alpha} \sigma_{\beta}$ and summed over all configurations:

$$
\frac{d}{d t}\left\langle\sigma_{\alpha} \sigma_{\beta}\right\rangle=-2\left\langle\sigma_{\alpha} \sigma_{\beta} w_{\alpha}\left(\sigma_{\alpha}, \sigma_{\beta}, \sigma_{\delta}\right)\right\rangle-2\left\langle\sigma_{\alpha} \sigma_{\beta} w_{\beta}\left(\sigma_{\alpha}, \sigma_{\beta}, \sigma_{\delta}\right)\right\rangle
$$

The equations for $\left\langle\sigma_{\beta} \sigma_{\delta}\right\rangle$ and $\left\langle\sigma_{\delta} \sigma_{\alpha}\right\rangle$ are also obtained in the same way:

$$
\begin{aligned}
\frac{d}{d t}\left\langle\sigma_{\beta} \sigma_{\delta}\right\rangle & =-2\left\langle\sigma_{\beta} \sigma_{\delta} w_{\beta}\left(\sigma_{\alpha}, \sigma_{\beta}, \sigma_{\delta}\right)\right\rangle-2\left\langle\sigma_{\beta} \sigma_{\delta} w_{\delta}\left(\sigma_{\alpha}, \sigma_{\beta}, \sigma_{\delta}\right)\right\rangle \\
\frac{d}{d t}\left\langle\sigma_{\delta} \sigma_{\alpha}\right\rangle & =-2\left\langle\sigma_{\delta} \sigma_{\alpha} w_{\delta}\left(\sigma_{\alpha}, \sigma_{\beta}, \sigma_{\delta}\right)\right\rangle-2\left\langle\sigma_{\delta} \sigma_{\alpha} w_{\alpha}\left(\sigma_{\alpha}, \sigma_{\beta}, \sigma_{\delta}\right)\right\rangle
\end{aligned}
$$


Note that correlations of two cell states represent the relative activity of the two cells. Accordingly, it makes a good measure of the different responses between two cells. Similarly, the equation for correlations of three cell states is given by

$$
\begin{aligned}
\frac{d}{d t}\left\langle\sigma_{\alpha} \sigma_{\beta} \sigma_{\delta}\right\rangle= & -2\left\langle\sigma_{\alpha} \sigma_{\beta} \sigma_{\delta} w_{\alpha}\left(\sigma_{\alpha}, \sigma_{\beta}, \sigma_{\delta}\right)\right\rangle-2\left\langle\sigma_{\alpha} \sigma_{\beta} \sigma_{\delta} w_{\beta}\left(\sigma_{\alpha}, \sigma_{\beta}, \sigma_{\delta}\right)\right\rangle \\
& -2\left\langle\sigma_{\alpha} \sigma_{\beta} \sigma_{\delta} w_{\delta}\left(\sigma_{\alpha}, \sigma_{\beta}, \sigma_{\delta}\right)\right\rangle
\end{aligned}
$$

Substituting the transition rates in Eq. 5 into Eqs. 7 to [12, we finally 
obtain equations for the states of the three cell types and their correlations:

$$
\begin{aligned}
& \tau \frac{d}{d t}\left\langle\sigma_{\alpha}\right\rangle=-w_{\alpha}^{\alpha}-w^{\alpha}\left\langle\sigma_{\alpha}\right\rangle-w_{\alpha \beta}^{\alpha}\left\langle\sigma_{\beta}\right\rangle-w_{\delta \alpha}^{\alpha}\left\langle\sigma_{\delta}\right\rangle-w_{\beta}^{\alpha}\left\langle\sigma_{\alpha} \sigma_{\beta}\right\rangle \\
& -w_{\alpha \beta \delta}^{\alpha}\left\langle\sigma_{\beta} \sigma_{\delta}\right\rangle-w_{\delta}^{\alpha}\left\langle\sigma_{\delta} \sigma_{\alpha}\right\rangle+w_{\beta \delta}^{\alpha}\left\langle\sigma_{\alpha} \sigma_{\beta} \sigma_{\delta}\right\rangle \\
& \tau \frac{d}{d t}\left\langle\sigma_{\beta}\right\rangle=-w_{\beta}^{\beta}-w_{\alpha \beta}^{\beta}\left\langle\sigma_{\alpha}\right\rangle-w^{\beta}\left\langle\sigma_{\beta}\right\rangle-w_{\beta \delta}^{\beta}\left\langle\sigma_{\delta}\right\rangle-w_{\alpha}^{\beta}\left\langle\sigma_{\alpha} \sigma_{\beta}\right\rangle \\
& -w_{\delta}^{\beta}\left\langle\sigma_{\beta} \sigma_{\delta}\right\rangle-w_{\alpha \beta \delta}^{\beta}\left\langle\sigma_{\delta} \sigma_{\alpha}\right\rangle-w_{\delta \alpha}^{\beta}\left\langle\sigma_{\alpha} \sigma_{\beta} \sigma_{\delta}\right\rangle \\
& \tau \frac{d}{d t}\left\langle\sigma_{\delta}\right\rangle=-w_{\delta}^{\delta}-w_{\delta \alpha}^{\delta}\left\langle\sigma_{\alpha}\right\rangle-w_{\beta \delta}^{\delta}\left\langle\sigma_{\beta}\right\rangle-w^{\delta}\left\langle\sigma_{\delta}\right\rangle-w_{\alpha \beta \delta}^{\delta}\left\langle\sigma_{\alpha} \sigma_{\beta}\right\rangle \\
& -w_{\beta}^{\delta}\left\langle\sigma_{\beta} \sigma_{\delta}\right\rangle-w_{\alpha}^{\delta}\left\langle\sigma_{\delta} \sigma_{\alpha}\right\rangle-w_{\alpha \beta}^{\delta}\left\langle\sigma_{\alpha} \sigma_{\beta} \sigma_{\delta}\right\rangle \\
& \tau \frac{d}{d t}\left\langle\sigma_{\alpha} \sigma_{\beta}\right\rangle=-\left(w_{\alpha \beta}^{\alpha}+w_{\alpha \beta}^{\beta}\right)-\left(w_{\beta}^{\alpha}+w_{\beta}^{\beta}\right)\left\langle\sigma_{\alpha}\right\rangle-\left(w_{\alpha}^{\alpha}+w_{\alpha}^{\beta}\right)\left\langle\sigma_{\beta}\right\rangle \\
& -\left(w_{\alpha \beta \delta}^{\alpha}+w_{\alpha \beta \delta}^{\beta}\right)\left\langle\sigma_{\delta}\right\rangle-\left(w^{\alpha}+w^{\beta}\right)\left\langle\sigma_{\alpha} \sigma_{\beta}\right\rangle \\
& -\left(w_{\delta \alpha}^{\alpha}+w_{\delta \alpha}^{\beta}\right)\left\langle\sigma_{\beta} \sigma_{\delta}\right\rangle-\left(w_{\beta \delta}^{\alpha}+w_{\beta \delta}^{\beta}\right)\left\langle\sigma_{\delta} \sigma_{\alpha}\right\rangle \\
& -\left(w_{\delta}^{\alpha}+w_{\delta}^{\beta}\right)\left\langle\sigma_{\alpha} \sigma_{\beta} \sigma_{\delta}\right\rangle \\
& \tau \frac{d}{d t}\left\langle\sigma_{\beta} \sigma_{\delta}\right\rangle=-\left(w_{\beta \delta}^{\beta}+w_{\beta \delta}^{\delta}\right)-\left(w_{\alpha \beta \delta}^{\beta}+w_{\alpha \beta \delta}^{\delta}\right)\left\langle\sigma_{\alpha}\right\rangle-\left(w_{\delta}^{\beta}+w_{\delta}^{\delta}\right)\left\langle\sigma_{\beta}\right\rangle \\
& -\left(w_{\beta}^{\beta}+w_{\beta}^{\delta}\right)\left\langle\sigma_{\delta}\right\rangle-\left(w_{\delta \alpha}^{\beta}+w_{\delta \alpha}^{\delta}\right)\left\langle\sigma_{\alpha} \sigma_{\beta}\right\rangle \\
& -\left(w^{\beta}+w^{\delta}\right)\left\langle\sigma_{\beta} \sigma_{\delta}\right\rangle-\left(w_{\alpha \beta}^{\beta}+w_{\alpha \beta}^{\delta}\right)\left\langle\sigma_{\delta} \sigma_{\alpha}\right\rangle \\
& -\left(w_{\alpha}^{\beta}+w_{\alpha}^{\delta}\right)\left\langle\sigma_{\alpha} \sigma_{\beta} \sigma_{\delta}\right\rangle \\
& \tau \frac{d}{d t}\left\langle\sigma_{\delta} \sigma_{\alpha}\right\rangle=-\left(w_{\delta \alpha}^{\delta}+w_{\delta \alpha}^{\alpha}\right)-\left(w_{\delta}^{\delta}+w_{\delta}^{\alpha}\right)\left\langle\sigma_{\alpha}\right\rangle-\left(w_{\alpha \beta \delta}^{\delta}+w_{\alpha \beta \delta}^{\alpha}\right)\left\langle\sigma_{\beta}\right\rangle \\
& -\left(w_{\alpha}^{\delta}+w_{\alpha}^{\alpha}\right)\left\langle\sigma_{\delta}\right\rangle-\left(w_{\beta \delta}^{\delta}+w_{\beta \delta}^{\alpha}\right)\left\langle\sigma_{\alpha} \sigma_{\beta}\right\rangle \\
& -\left(w_{\alpha \beta}^{\delta}+w_{\alpha \beta}^{\alpha}\right)\left\langle\sigma_{\beta} \sigma_{\delta}\right\rangle-\left(w^{\delta}+w^{\alpha}\right)\left\langle\sigma_{\delta} \sigma_{\alpha}\right\rangle \\
& -\left(w_{\beta}^{\delta}+w_{\beta}^{\alpha}\right)\left\langle\sigma_{\alpha} \sigma_{\beta} \sigma_{\delta}\right\rangle \\
& \tau \frac{d}{d t}\left\langle\sigma_{\alpha} \sigma_{\beta} \sigma_{\delta}\right\rangle=-\left(w_{\alpha \beta \delta}^{\alpha}+w_{\alpha \beta \delta}^{\beta}+w_{\alpha \beta \delta}^{\delta}\right)-\left(w_{\beta \delta}^{\alpha}+w_{\beta \delta}^{\beta}+w_{\beta \delta}^{\delta}\right)\left\langle\sigma_{\alpha}\right\rangle \\
& -\left(w_{\delta \alpha}^{\alpha}+w_{\delta \alpha}^{\beta}+w_{\delta \alpha}^{\delta}\right)\left\langle\sigma_{\beta}\right\rangle-\left(w_{\alpha \beta}^{\alpha}+w_{\alpha \beta}^{\beta}+w_{\alpha \beta}^{\delta}\right)\left\langle\sigma_{\delta}\right\rangle \\
& -\left(w_{\delta}^{\alpha}+w_{\delta}^{\beta}+w_{\delta}^{\delta}\right)\left\langle\sigma_{\alpha} \sigma_{\beta}\right\rangle-\left(w_{\alpha}^{\alpha}+w_{\alpha}^{\beta}+w_{\alpha}^{\delta}\right)\left\langle\sigma_{\beta} \sigma_{\delta}\right\rangle \\
& -\left(w_{\beta}^{\alpha}+w_{\beta}^{\beta}+w_{\beta}^{\mathrm{d}}\right\rangle\left\langle\sigma_{\delta} \sigma_{\alpha}\right\rangle-\left(w^{\alpha}+w^{\beta}+w^{\delta}\right)\left\langle\sigma_{\alpha} \sigma_{\beta} \sigma_{\delta} \not \perp 3\right)
\end{aligned}
$$




\subsection{Glucose homeostasis}

Heretofore we have focused on the cellular interactions at a given glucose level. To study dynamics of glucose homeostasis, however, we should also take into account the change of the glucose level and incorporate another equation for glucose regulation into the model. Based on the fact that $\alpha$ and $\beta$-cells secrete glucagon and insulin, respectively, raising and reducing the glucose level, the equation for the glucose level $G$ is taken to be

$$
\tau_{G} \frac{d G}{d t}=\frac{1+\left\langle\sigma_{\alpha}\right\rangle}{2}-\frac{1+\left\langle\sigma_{\beta}\right\rangle}{2}
$$

where $\tau_{G}$ is the characteristic time for the hormones to regulate the glucose level. It is expected that $\tau_{G}$ is larger than the characteristic time $\tau$ of the change in cell states. Equation 14 describes the decrease or increase of the glucose level when $\alpha$-cells or $\beta$-cells are active $\left(\sigma_{\alpha}=1\right.$ or $\left.\sigma_{\beta}=1\right)$. Here, for simplicity, we have used the same characteristic time $\tau_{G}$ for glucagon and insulin to regulate glucose levels. Having different time constants turns out merely to shift the stationary level of blood glucose. To sum, we have a total of eight differential equations given by Eqs. 13 and 14, which describe the process of glucose homeostasis.

\section{Results}

\subsection{Asymmetric interactions between $\alpha$ - and $\beta$-cells}

In our model, activities of $\alpha-, \beta$-, and $\delta$-cells are determined by the external glucose level together with feedback loops of intercellular interactions. 
A given cell, subject to a glucose stimulus, secretes hormone which influences the behavior of neighboring cells. In response, the neighboring cells reversely influence the given cell. These mutual interactions through hormones constitute the feedback loop which is widely employed for advanced system control in engineering (Bechhoefer, 2005).

The interactions between $\alpha$ - and $\beta$-cells are asymmetric: While glucagon secreted from $\alpha$-cells enhances insulin secretion of $\beta$-cells (Brereton et al., 2007; Samols et al., 1965, Soria et al., 2000), insulin inhibits glucagon secretion (Cherrington et al., 1976, Franklin et al., 2005; Ravier \& Rutter, 2005; Samols \& Harrison, 1976; Soria et al., 2000).

The former positive interaction to the counterpart cells may seem strange, but it eventually contributes to the construction of a negative feedback loop for both cells. At low glucose levels, $\alpha$-cells secrete glucagon, which enhances insulin secretion. In turn, insulin inhibits the glucagon secretion of $\alpha$-cells. Therefore, their interactions as a whole tend to suppress the glucagon secretion from $\alpha$-cells. Similar negative feedback operates when $\beta$-cells are activated by high glucose concentration. It is noteworthy that this feedback works more efficiently in case that the glucose level varies. At a static glucose level, it should be difficult for the mutual interactions between $\alpha$ - and $\beta$-cells to arise simultaneously because insulin and glucagon are secreted at different glucose levels.

In general, a negative feedback favors stability of a system because it attenuates overaction of the system such as overshoot or undershoot. The negative feedbacks in an islet system contribute to the stable recovery to the normal glucose level $G_{\infty}$, when the system is externally perturbed by stimuli such as a glucose dose. The normal glucose level $G_{\infty}$, reached by 
$G\left(\equiv \tilde{G}-\tilde{G}_{0}\right)$ at stationarity, depends on the cellular interactions shown in Fig. 2. The asymmetric interaction $J_{1}$ lowers the basal glucose level because $\alpha$-cells activate $\beta$-cells which secret insulin and thus reduces the glucose level. In addition, the inhibitory interaction $J_{2}$ of $\delta$-cells, albeit the same for $\alpha$ - and $\beta$-cells, suppresses the activity of $\beta$-cells more than that of $\alpha$-cells at the normal glucose level, because the activity of $\beta$-cells is higher than that of $\alpha$-cells resulting from the asymmetric interaction between $\alpha$-and $\beta$-cells. Accordingly, the basal glucose level tends to increase as the strength $J_{2}$ of the inhibitory interaction is increased.

Figure 3 demonstrates the smooth recovery of the glucose level in the presence of cellular interactions (solid line), compared with the somewhat erratic recovery, once reaching low glucose levels, in the absence of the interactions (dashed line). For comparison, we also consider the behavior in the case of symmetric interactions between $\alpha$ - and $\beta$-cells, i.e., where glucagon inhibits insulin secretion and vice versa, only to find even more erratic recovery (see the dotted line). Shown here is the recovery from the high glucose state $\left[G=1 \mathrm{mM}\right.$ (or $\left.\tilde{G}=\tilde{G}_{0}+1 \mathrm{mM}\right),\left\langle\sigma_{\alpha}\right\rangle=-1$, and $\left.\left\langle\sigma_{\beta}\right\rangle=1\right]$. The recovery from a low glucose state gives the same results (data not shown) although such erratic recovery is more pronounced for the glucose level starting from a higher value.

To examine the stability in approaching the normal glucose level, we define the balance function

$$
b(G) \equiv \tau_{G} \frac{d G}{d t}=\frac{1+\left\langle\sigma_{\alpha}\right\rangle}{2}-\frac{1+\left\langle\sigma_{\beta}\right\rangle}{2}
$$


which describes the glucose level change during the characteristic time. Since the activity of cells represents their hormone secretion, $b(G)$ appropriately describes the effectiveness of the glucose regulation by $\alpha$ - and $\beta$-cells. If the characteristic time $\tau_{G}$ of glucose regulation is much larger than the characteristic time $\tau$ of cell responses in Eq. 13, i.e., $\tau \ll \tau_{G}$, the glucose level should be in a quasi-stationary state at time $t$ shorter than $\tau_{G}$. Then the fast dynamics of cell states in Eq.13]saturates rapidly at a given glucose level and the seven variables, activities and correlations, reach their fixed points depending on the glucose level $G$. In particular $\left\langle\sigma_{\alpha}\right\rangle$ and $\left\langle\sigma_{\beta}\right\rangle$ depend on $G$, giving the balance function in Eq. 15 as a function of $G$, with a fixed point at $G=G_{\infty}$ (see Fig. 4). At low glucose levels $\left(G<G_{\infty}\right)$, we have the balance function greater than zero $(b>0)$, or $d G / d t>0$, thus the glucose level grows with time. At high glucose levels $\left(G>G_{\infty}\right)$, the opposite behavior arises. The resulting flow of the balance function is illustrated by the arrows in Fig. 4 and it is concluded that the balance function correctly describes glucose homeostasis. Further, the slope of $b(G)$ near the fixed point $G=G_{\infty}$ represents how smoothly the glucose level approaches the normal level: The slope of the balance function for the asymmetric interaction is small at $G=G_{\infty}$, which results in the smooth recovery of the normal glucose level shown in Fig. 3. This result is more evident with the interaction strength $J_{1}$ larger and the characteristic time $\tau_{G}$ shorter.

If $\alpha$ - and $\beta$-cells would inhibit each other, how should the result change? As suggested already (Saunders et al., 1998), the bidirectional inhibitory interactions seem to be optimal in view of that $\alpha$ - and $\beta$-cells play opposite roles in glucose regulation. Remarkably, however, such symmetric interac- 
tions turn out to result in dynamically unstable responses, as shown by the dotted line in Fig. 3, If this were the case, glucagon secreted by $\alpha$-cells at low glucose levels would suppress $\beta$-cells from secreting insulin. As the secretion of insulin decreases, so would the inhibitory effects of insulin on the glucagon secretion diminish. It should thus follow that glucagon secretion is not negatively controlled, implying more glucagon secretion. Such an apparent positive feedback loop, enhancing hormone secretion, gives rise to an instability in the islet system (see Fig. 3).

\subsection{Inhibitory interactions of $\delta$-cells}

\subsubsection{Suppression of co-secretion from $\alpha$ - and $\beta$-cells}

There is basal hormone secretion from $\alpha$ - and $\beta$-cells even at the normal glucose level (Cherrington et al., 1976), where it is not necessary to change the blood glucose concentration with the help of glucagon or insulin. Obviously, the simultaneous secretion of glucagon and insulin at the normal level should be minimized because the opposite effects of the two would cancel out, nullifying the net effects on the glucose level. Such wasteful cosecretion of counteracting hormones can be prevented by $\delta$-cells secreting somatostatin, which inhibits secretion of both glucagon and insulin.

In our model, the average activity of cells is given by $(1+\langle\sigma\rangle) / 2$. Accordingly, the average cell state $\langle\sigma\rangle= \pm 1$ means that all cells are active/silent; in particular $\langle\sigma\rangle=0$ corresponds to half of the cells being active. In the absence of the inhibitory interaction of $\delta$-cells, Fig. 5(a) shows that both $\left\langle\sigma_{\alpha}\right\rangle$ and $\left\langle\sigma_{\beta}\right\rangle$ take values greater than -1 even at the normal glucose level. 
Namely, fluctuations associated with the biological uncertainty $\Theta$ have some fraction of cells still active, leading to basal hormone secretion. Here the presence of inhibitory interactions of $\delta$-cells lowers the basal activity of $\alpha$ and $\beta$-cells, as shown in Fig. 5(b), which reduces co-secretion of the counteracting hormones, glucagon and insulin.

Figure [6] displays the relation between $\left\langle\sigma_{\alpha}\right\rangle$ and $\left\langle\sigma_{\beta}\right\rangle$, in the absence $\left(J_{2}=0 \mathrm{mM}\right)$ and presence $\left(J_{2}=2 \mathrm{mM}\right)$ of the inhibitory interaction of $\delta$ cells. The system at low or high glucose levels is described by the upper left or lower right parts of the curves on the $\left(\left\langle\sigma_{\beta}\right\rangle,\left\langle\sigma_{\alpha}\right\rangle\right)$ plane, respectively. Namely, when the glucose concentration is low, $\alpha$ - and $\beta$-cells are in high and in low activity, respectively $\left(\left\langle\sigma_{\alpha}\right\rangle>0\right.$ and $\left.\left\langle\sigma_{\beta}\right\rangle<0\right)$; this is reversed at high glucose concentrations. It is manifested that the inhibitory interaction of $\delta$-cells reduces simultaneous activation of $\alpha$ - and $\beta$-cells. Compared with the result for $J_{2}=0 \mathrm{mM}$ (dashed line), the result for $J_{2}=2 \mathrm{mM}$ (solid line) shows that the activity of $\beta$ - or $\alpha$-cells is reduced substantially at high or low glucose levels. In particular $\alpha$-cells remain almost silent $\left(\left\langle\sigma_{\alpha}\right\rangle \approx-1\right)$ at high glucose levels. Note, however, that those endocrine cells are not totally silent at given glucose levels and still exhibit residual activity, which results from fluctuations in the glucose responses of the cells. Interestingly, it was suggested that such basal hormone secretion also plays an effective role: The minimal basal secretion of glucagon compensates the glucose uptake in the liver while basal secretion of insulin inhibits over-secretion of the basal glucagon (Cherrington et al., 1976). 


\subsubsection{Enhancement of glucose dose-responses of $\beta$-cells}

Another consequence of the inhibitory interaction of $\delta$-cells is the shift of glucose dose-responses for insulin secretion to the right direction. This is associated with the increased control of $\beta$-cells by $\delta$-cells at high glucose levels. Figure 7 indeed shows that the shift leads to more conspicuous glucose responses of $\beta$-cells at high glucose levels. In general $\beta$-cells are coupled with each other through gap-junction channels, which help the cells synchronize their behaviors (Sherman \& Rinzel, 1991). A $\beta$-cell cluster thus tends to produce all-or-none glucose responses (Soria et al., 2000). In the real islet, on the other hand, $\delta$-cells, with their inhibitory interactions depending on the glucose level, can modify the glucose dose-response of $\beta$-cells. Accordingly, insulin response can be more pronounced at high glucose levels $(G>0)$.

It is observed that some primitive animals have only $\beta$ - and $\delta$-cells in their islets, unlike the mammals whose islets contain $\alpha$-cells as well as $\beta$ and $\delta$-cells (Falkmer, 1985). This difference could perhaps be attributed to an evolutionary adaptation. At early evolutionary stages, the islet might be a passive system: Without $\alpha$-cells directly increasing the glucose level, the glucose level should increase passively as a result of the decrease in insulin secretion. Still, the precise glucose dose-responses at high glucose levels could be possible with $\delta$-cells. At later stages, equipped with $\alpha$ cells, the islet became an active system with regard to glucose regulation. It is of interest that this evolutionary change is correlated with the fact that $\beta$ - and $\delta$-cells are closer to each other than $\alpha$-cells in the develop- 
ment of a stem cell (Kemp et al., 2003). In addition, $\beta$ - and $\delta$-cells have functional similarities of using ATP-dependent $\mathrm{K}^{+}$channels in glucose responses (Quesada et al., 2006; Quesada et al., 1999).

\section{Discussions}

The islet of Langerhans is a precise system that controls the glucose level through the use of three main types of endocrine cells. Here it is of interest to investigate whether the existing interactions between those cells are beneficial for glucose homeostasis. There are some evidence for the critical role of the interactions, which may not obviously be addressed by probing $\alpha$ - and $\beta$-cells separately. The molecular mechanism of how $\alpha$-cells regulate glucagon secretion at variable glucose levels is still not clearly understood (Gromada et al., 2007). Several works attempted to explain this by means of the interactions between $\alpha$ - and $\beta$-cells: At high glucose levels, glucagon secretion is inhibited by insulin, GABA, or $\mathrm{Zn}^{2+}$ secreted from $\beta$-cells (Gromada et al., 2007; Ishihara et al., 2003). There is also a hypothesis that glucose has direct effects on $\alpha$-cells through endoplasmic reticulum $\mathrm{Ca}^{2+}$ storage (Vieira et al., 2006). Another evidence for the role of cellular interactions in glucose homeostasis comes from hyperglucagonomia, which occurs in diabetics at abnormally high glucose levels. It appears paradoxical that the glucagon levels of such patients are high even though the blood glucose levels are high enough to make $\alpha$-cells silent (Gromada et al., 2007). This puzzling result can be explained on the basis of cellular interactions in an islet (Franklin et al., 2005; Rorsman et al., 1989; Takahashi et al., 2006). 
Note that there is also another explanation of this phenomenon in terms of the peculiar glucose dose-responses of (rat) $\alpha$-cells (Kemp et al., 2003).

In contrast, there also exist a few reports that some cellular interactions may not exist and are not necessary for glucose homeostasis: It has been proposed that the microcirculation from $\beta$ - to peripheral $\alpha$ - and $\delta$-cells prohibits the paracrine action from non- $\beta$ to $\beta$-cells (Wayland, 1997). In addition, it has recently been reported that islet transplantation is successful in recovering from hyperglycaemia with only $\beta$-cell clusters (King et al., 2007).

Nevertheless, the existence of the receptors of signalling molecules such as insulin, glucagon, somatostatin, glutamate, and GABA, which are expressed in pancreatic endocrine cells, apparently implicates their physiological roles in the fine control of glucose levels (Gromada et al., 2007; Strowski \& Blake, 2008). A better understanding of this tissue, therefore, will contribute to more advanced medical treatment of diabetes than the current one relying mostly on insulin. For example, it is conceivable to use other hormones such as glucagon and somatostatin for more active and precise glucose control.

A variety of complicated interactions in an islet makes it difficult to recognize their roles, and existing experiments as to those interactions have focused mostly on static responses of the endocrine cells. However, it is likely that the cellular interactions actually contribute to dynamical responses to glucose. In this study, therefore, to understand the role of intercellular interactions between $\alpha$-, $\beta$-, and $\delta$-cells, we have proposed an islet model and investigated the effects of integrated intercellular communications between those cells in glucose homeostasis. Our mathematical model can systemati- 
cally include all the cellular interactions and identify their effects on static and/or dynamic responses to external glucose changes. It also takes individual heterogeneities into consideration, e.g., in glucose sensitivity; the basal hormone secretion at the normal glucose level reflects that some cells can be active to secrete hormones even though most of the cells are silent at that glucose level. The small variations in glucose responses among homologous cells may contribute crucially to the cellular interactions between heterologous cells, which are actually activated in quite different glucose concentrations, because the heterogeneous responses of homologous cells can lead to an overlap in the activation between the heterologous cells. ¿From this model, it has been revealed that the interactions give more stable, efficient, and accurate control of glucose: First, asymmetric interactions between $\alpha$ and $\beta$-cells contribute to the dynamic stability when the glucose level, perturbed from the normal level, recovers to the latter. Second, the interactions of somatostatin for glucagon and insulin secretion prevent their wasteful cosecretion at the normal glucose level. In addition, at high glucose levels, the inhibition by $\delta$-cells modifies glucose dose-responses of insulin secretion. For a more realistic and accurate understanding, it would be necessary to know the physiological values of the model parameters. In particular, the relative effects of the direct glucose stimulus $G$ and paracrine interactions $J$ on the states of endocrine cells should be identified.

Here it is proposed that these predictions can be verified in experiment. As for the role of $\delta$-cells, our results may be confirmed through the use of cell clusters of different compositions of cell-types, for which the culture method was used in the existing study (Pipeleers et al., 1982). Another 
prediction related with the asymmetric interactions between $\alpha$ - and $\beta$-cells needs to be verified in vivo experiment on transgenic mice because the effects should arise in the dynamics of whole-body glucose regulation. Note that the specific cellular interaction may be blocked selectively in knockout mice lacking specific hormone receptors in an endocrine cell (Diao et al., 2005; Sorensen et al., 2006).

Beyond the interactions between endocrine cells analyzed in this study, there exist reports that $\delta$-cells are also influenced by $\alpha$ - and $\beta$-cells (Unger \& Orci, 1977) and these paracrine interactions should be considered with the microcirculation of hormones in an islet as described above (Wayland, 1997). It has also been reported that there exist autocrine interactions via which a cell is affected by its own hormone secretion (Aspinwall et al., 1999; Cabrera et al., 2008).

Furthermore, input from exocrine cells (Bertelli et al., 2001; Bishop \& Polak, 1997; Wayland, 1997) and glucose-sensing neurons (Schuit et al., 2001) have been suggested. There may thus be more complex communications in the pancreas for glucose homeostasis, which are left for further study. Finally, we also point out that the mathematical model proposed can be generalized to describe cellular interactions in other systems, e.g., neural networks consisting of excitatory and inhibitory couplings.

\section{Acknowledgments}

We thank D. Gardner-Hofatt and W. Heuett for useful comments on the manuscript. M.Y.C. thanks Asia Pacific Center for Theoretical Physics, where part of this work was performed, for hospitality. This work was sup- 
ported in part by the KOSEF/MOST grant through National Core Research Center for Systems Bio-Dynamics and by the KOSEF-CNRS Cooperative Program.

\section{References}

Aspinwall, C. A., Lakey, J. R. T. \& Kennedy, R. T. (1999). Insulinstimulated insulin secretion in single pancreatic beta cells. J. Biol. Chem. 274, 6360-6365.

Bechhoefer, J. (2005). Feedback for physicists: a tutorial essay on control. Rev. Mod. Phys. 77, 783-836.

Bertelli, E., Regoli, M., Orazioli, D. \& Bendayan, M. (2001). Association between islets of Langerhans and pancreatic ductal system in adult rat. where endocrine and exocrine meed together? Diabetologia, 44, 575584.

Bishop, A. E. \& Polak, J. M. (1997). The anatomy, organization and ultrastructure of the islets of Langerhans. In Textbook of diabetes, (Pickup, J. C. \& Williams, G., eds),. Blackwell Science, Mass. Chap. 6.

Brereton, H., Carvell, M. J., Persaud, S. J. \& Jones, P. M. (2007). Islet $\alpha$-cells do not influence insulin secretion from $\beta$-cells through cell-cell contact. Endocr. 31, 61-65.

Brice, N. L., Varadi, A., Ashcroft, S. J. H. \& Molnar, E. (2002). Metabotropic glutamate and $\mathrm{GABA}_{b}$ receptors contribute to the mod- 
ulation of glucose-stimulated insulin secretion in pancreatic beta cells. Diabetologia, 45, 242-252.

Brissova, M., Fowler, M. J., Nicholson, W. E., Chu, A., Hirshberg, B., Harlan, D. M. \& Powers, A. C. (2005). Assessment of human pancreatic islet architecture and composition by laser scanning confocal microscopy. $J$. Histochem. Cytochem. 53, 1087-1097.

Cabrera, O., Jacques-Silva, M. C., Speler, S., Yang, S. N., Köhler, M., Fachado, A., Vieira, E., Zilerath, J. R., Kibbey, R., Berman, D. M., Kenyon, N. S., Ricordi, C., Caicedo, A. \& Berggren, P. O. (2008). Glutamate is a positive autocrine signal for glucagon release. Cell Metab. 7, 545-554.

Cherrington, A. D., Chiasson, J. L., Liljenquist, J. E., Jennings, A. S., Keller, U. \& Lacy, W. W. (1976). The role of insulin and glucagon in the regulation of basal glucose production in the postabsorptive dog. $J$. Clin. Invest. 58, 1407-1418.

Daunt, M., Dale, O. \& Smith, P. A. (2006). Somatostatin inhibits oxidative respiration in pancreatic $\beta$-cells. Endocrinology, 147, 1527-1535.

Diao, J., Asghar, Z., Chan, C. B. \& Wheeler, M. B. (2005). Glucoseregulated glucagon secretion requires insulin receptor expression in pancreatic $\alpha$-cells. J. Biol. Chem. 280, 33487-33496.

Efendić, S., Enzmann, F., Nylén, A., Uvnäs-Wallensten, K. \& Luft, R. (1979). Effect of glucose/sulfonylurea interaction on release of insulin, 
glucagon, and somatostatin from isolated perfused rat pancreas. Proc. Natl. Acad. Sci. USA, 76, 5901-5904.

Falkmer, S. (1985). Comparative morphology of pancreatic islets in animals. In The diabetic pancreas, (Volk, B. W. \& Arquilla, E. R., eds),. Plenum Medical Book Company, New York and London. Chap. 2.

Franklin, I., Gromada, J., Gjinovci, A., Theander, S. \& Wollheim, C. B. (2005). $\beta$-cell secretory products activate $\alpha$-cell ATP-dependent potassium channels to inhibit glucagon release. Diabetes, 54, 1808-1815.

Franklin, I. K. \& Wollheim, C. B. (2004). GABA in the endocrine pancreas: its putative role as an islet cell paracrine-signalling molecule. J. Gen. Physiol. 123, 185-190.

Gilon, P., Bertrand, G., Loubatiéres-Mariani, M. M., Remacle, C. \& Henquin, J. C. (1991). The influence of $\gamma$-aminobutylic acid on hormone release by the mouse and rat endocrine pancreas. Endocrinology, 129, $2521-2529$.

Glauber, R. J. (1963). Time-dependent statistics of the Ising model. $J$. Math. Phys. 4, 294-307.

Gromada, J., Franklin, I. \& Wollheim, C. B. (2007). $\alpha$-cells of the endocrine pancreas: 35 years of research but the enigma remains. Endocrine Reviews, 28, 84-116.

Hopcroft, D. W., Mason, D. R. \& Scott, R. S. (1985). Structure-function 
relationships in pancreatic islets: support for intraislet modulation of insulin secretion. Endocrinology, 117, 2073-2080.

Ishihara, H., Maechler, P., Gjinovci, A., Herrera, P.-L. \& Wollheim, C. B. (2003). Islet $\beta$-cell secretion determines glucagon release from neighbouring $\alpha$-cells. Nat. Cell Biol. 5, 330-335.

Jo, J., Kang, H., Choi, M. Y. \& Koh, D. S. (2005). How noise and coupling induce bursting action potentials in pancreatic $\beta$-cells. Biophys. J. 89, $1534-1542$.

Kemp, D. M., Thomas, M. K. \& Habener, J. F. (2003). Developmental aspects of the endocrine pancreas. Rev. Endocr. Metab. Disord. 4, 517.

King, A. J. F., Fernandes, J. R., Hollister-Lock, J., Nienaber, C. E., BonnerWeir, S. \& Weir, G. C. (2007). Normal relationship of $\beta$ - and non- $\beta$-cells not needed for successful islet transplantation. Diabetes, 56, 23122318.

Moriyama, Y. \& Hayashi, M. (2003). Glutamate-mediated signalling in the islets of Langerhans: a thread entangled. Trends Pharmocol. Sci. 24, $511-517$.

Nadal, A., Quesada, I. \& Soria, B. (1999). Homologous and heterologous asynchronicity between identified $\alpha-, \beta$-, and $\delta$-cells within intact islets of langerhans in the mouse. J. Physiol. 517, 85-93. 
Orci, L. \& Unger, R. H. (1975). Functional subdivision of islets of Langerhans and possible role of D-cells. The Lancet, 2, 1243-1244.

Pipeleers, D. (1987). The biosociology of pancreatic B cells. Diabetologia, 30, 277-291.

Pipeleers, D., Veld, P. I., Maes, E. \& Winkel, M. V. D. (1982). Glucoseinduced insulin release depends on functional cooperation between islet cells. Proc. Natl. Acad. Sci. USA, 79, 7322-7325.

Quesada, I., Nadal, A. \& Soria, B. (1999). Different effects of tolbutamide and diazoxide in $\alpha^{-}, \beta$-, and $\delta$-cells within intact islets of Langerhans. Diabetes, 48, 2390-2397.

Quesada, I., Todorova, M. G. \& Soria, B. (2006). Different metabolic responses in alpha, beta and delta-cells of the islet of Langerhans monitored by redox confocal microscopy. Biophys. J. 90, 2641-2650.

Ravier, M. A. \& Rutter, G. A. (2005). Glucose or insulin, but not zinc ions, inhibits glucagon secretion from mouse pancreas $\alpha$-cells. Diabetes, 54, $1789-1797$.

Rorsman, P., Berggren, P. O., Bokvist, K., Ericson, H., Möhler, H., Östenson, C. G. \& Smith, P. A. (1989). Glucose-inhibition of glucagon secretion involves activation of $\mathrm{GABA}_{A}$-receptor chloride channels. $\mathrm{Na}$ ture, 341, 233-236.

Samols, E. \& Harrison, J. (1976). Intraislet negative insulin/glucagon feedback. Metabolism, 25, 1443-1447. 
Samols, E., Marri, G. \& Marks, V. (1965). Promotion of insulin secretion by glucagon. The Lancet, $\mathbf{2}, 415-416$.

Saunders, P. T., Koeslag, J. H. \& Wessels, J. A. (1998). Integral rein control in physiology. J. Theor. Biol. 194, 163-173.

Schuit, F. C., Huypens, P., Heimberg, H. \& Pipeleers, D. G. (2001). Glucose sensing in pancreatic $\beta$-cells: a model for the study of other glucoseregulated cells in gut, pancreas, and hypothalamus. Diabetes, 50, 1-11.

Sherman, A. \& Rinzel, J. (1991). Model for synchronization of pancreatic $\beta$-cells by gap junction coupling. Biophys. J. 59, 547-559.

Sherman, A., Rinzel, J. \& Keizer, J. (1988). Emergence of organized bursting in clusters of pancreatic $\beta$-cells by channel sharing. Biophys. J. 54, 411425.

Sorensen, H., Winzell, M. S., Bland, S. L., Fosgerau, K., Gelling, R. W., Nishimura, E. \& Ahren, B. (2006). Glucagon receptor knockout mice display increased insulin sensitivity and impaired $\beta$-cell function. Diabetes, 55, 3463-3469.

Soria, B., Andreu, E., Berná, G., Fuentes, E., Gil, A., León-Quinto, T., Martín, F., Montanya, E., Nadal, A., Reig, J. A., Ripoll, C., Roche, E., Sanchez-Andrés, J. V. \& Segura, J. (2000). Engineering pancreatic islets. Pflügers Arch. 440, 1-18.

Strowski, M. Z. \& Blake, A. D. (2008). Fuction and expression of somato- 
statin receptors of the endocrine pancreas. Mol. Cell. Endocrinol. 286, $169-179$.

Takahashi, R., Ishihara, H., Tamura, A., Yamaguchi, S., Yamada, T., Takei, D., Katagiri, H., Endou, H. \& Oka, Y. (2006). Cell type-specific activation of metabolism reveals that $\beta$-cell secretion suppresses glucagon release from $\alpha$-cells in rat pancreatic islets. Am. J. Physiol. Endocrinol. Metab. 290, 308-316.

Unger, R. H. \& Orci, L. (1977). Possible roles of the pancreatic D-cell in the normal and diabetic states. Diabetes, 26, 241-244.

Vieira, E., Salehi, A. \& Gylfe, E. (2006). Glucose inhibits glucagon secretion by a direct effect on mouse pancreatic alpha cells. Diabetologia, 50, $370-379$.

Wayland, H. (1997). Microcirculation in pancreatic function. Microsc. Res. Tech. 37, 418-433.

Wendt, A., Birnir, B., Buschard, K., Gromada, J., Salehi, A., Sewing, S., Rorsman, P. \& Braun, M. (2004). Glucose inhibition of glucagon secretion from rat $\alpha$-cells is mediated by GABA released from neighboring $\beta$-cells. Diabetes, 53, 1038-1045. 


\section{Tables}

Table 1: Coefficients in the transition rate. Here $k^{x} \equiv\left(g^{x}+j_{1}^{x}+j_{2}^{x}+\right.$ $\left.g^{x} j_{1}^{x} j_{2}^{x}\right)\left(1+g^{x} j_{1}^{x}+j_{1}^{x} j_{2}^{x}+j_{2}^{x} g^{x}\right)^{-1}$ with $x$ denoting $\alpha$, $\beta$, or $\delta$. Parameters $g^{x}, j_{1}^{x}$, and $j_{2}^{x}$ are given in Table 2 .

\begin{tabular}{cc}
\hline Coefficient & Value \\
\hline$w^{x}$ & 1 \\
$w_{\alpha}^{x}$ & $k^{x}$ \\
$w_{\beta}^{x}$ & $k^{x} j_{1}^{x}$ \\
$w_{\delta}^{x}$ & $k^{x} j_{2}^{x}$ \\
$w_{\alpha \beta}^{x}$ & $j_{1}^{x}$ \\
$w_{\beta \delta}^{x}$ & $j_{1}^{x} j_{2}^{x}$ \\
$w_{\delta \alpha}^{x}$ & $j_{2}^{x}$ \\
$w_{\alpha \beta \delta}^{x}$ & $k^{x} j_{1}^{x} j_{2}^{x}$ \\
\hline
\end{tabular}


Table 2: Parameters in the coefficients of the transition rate.

\begin{tabular}{c|ccc}
\hline$x$ & $\alpha$ & $\beta$ & $\delta$ \\
\hline$g^{x}$ & $\tanh (G / 2 \Theta)$ & $\tanh (-G / 2 \Theta)$ & $\tanh (-m G / 2 \Theta)$ \\
$j_{1}^{x}$ & $\tanh \left(J_{1} / 4 \Theta\right)$ & $\tanh \left(-J_{1} / 4 \Theta\right)$ & 0 \\
$j_{2}^{x}$ & $\tanh \left(J_{2} / 4 \Theta\right)$ & $\tanh \left(J_{2} / 4 \Theta\right)$ & 0 \\
\hline
\end{tabular}




\section{Figure Legends}

\section{Figure 1.}

Schematic diagram of cellular interactions between $\alpha-, \beta$-, and $\delta$-cells. The arrow represents enhancement while bars represent inhibition. Here the intercellular interactions between two cells are present only when both are in active states.

Figure 2,

Stationary glucose level $G_{\infty}$, depending on the cellular interaction strengths $J_{1}$ and $J_{2}$. Note that $G_{\infty}$ measures the stationary level relative to the fasting glucose level $\tilde{G}_{0}$ in the absence of cellular interactions.

\section{Figure 3 .}

Time evolution of the glucose level $G$, depending on the interactions between $\alpha$ - and $\beta$-cells. Starting from the high-glucose state $\left[\left\langle\sigma_{\alpha}\right\rangle=-1\right.$ and $\left\langle\sigma_{\beta}\right\rangle=1$ at $G=1 \mathrm{mM}$ (or $\tilde{G}=\tilde{G}_{0}+1 \mathrm{mM}$ )], the system recovers eventually the normal glucose level $G_{\infty}$. The time constants are taken to be $\tau=\tau_{G}=1$ for simplicity and the cellular interactions have strengths $J_{1}=2 \mathrm{mM}$ and $J_{2}=0 \mathrm{mM}$.

\section{Figure 4 .}

Balance function for glucose regulation, depending on the interactions between $\alpha$ - and $\beta$-cells. The strengths of cellular interactions are $J_{1}=2 \mathrm{mM}$ and $J_{2}=0 \mathrm{mM}$. 


\section{Figure 5.}

Time evolution of the average states $\left\langle\sigma_{\alpha}\right\rangle$ and $\left\langle\sigma_{\beta}\right\rangle$ of $\alpha$ - and $\beta$-cells, starting initially from the high-glucose state $\left\langle\sigma_{\alpha}\right\rangle=-1$ and $\left\langle\sigma_{\beta}\right\rangle=1$ at $G=1 \mathrm{mM}$, during the recovery to the normal glucose level. The asymmetric interactions between $\alpha$ - and $\beta$-cells have the strength $J_{1}=2 \mathrm{mM}$ whereas the inhibitory interactions of $\delta$-cells are absent in (a) $J_{2}=0 \mathrm{mM}$ but present in (b) $J_{2}=$ $2 \mathrm{mM}$.

\section{Figure 6.}

The average state $\left\langle\sigma_{\alpha}\right\rangle$ of $\alpha$-cells versus $\left\langle\sigma_{\beta}\right\rangle$ of $\beta$-cells for the asymmetric interaction $J_{1}=2 \mathrm{mM}$, in the absence $\left(J_{2}=0 \mathrm{mM}\right)$ and presence $\left(J_{2}=\right.$ $2 \mathrm{mM}$ ) of the inhibitory interaction of $\delta$-cells. The dotted line along the diagonal represents the stationary condition $\left\langle\sigma_{\alpha}\right\rangle=\left\langle\sigma_{\beta}\right\rangle$.

\section{Figure 7 ,}

Glucose dose-responses in the activity of $\beta$-cells for the inhibitory interaction $J_{2}=0$ and $2 \mathrm{mM}$. The asymmetric interactions are taken to have the strength $J_{1}=2 \mathrm{mM}$. 


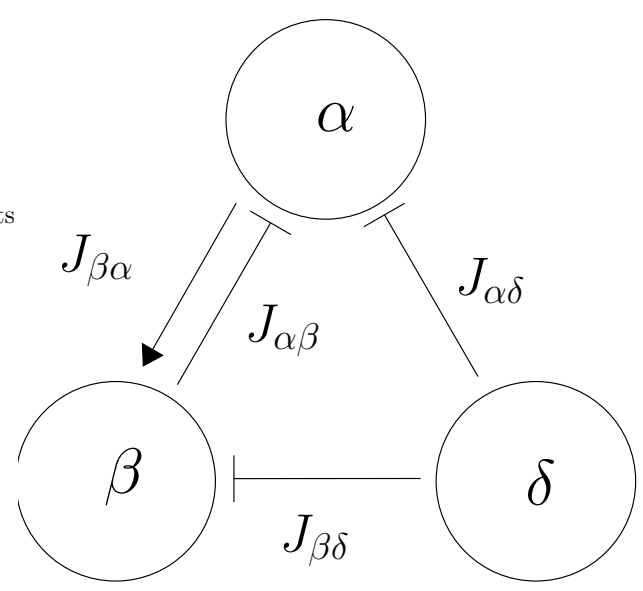

Figure 1: 


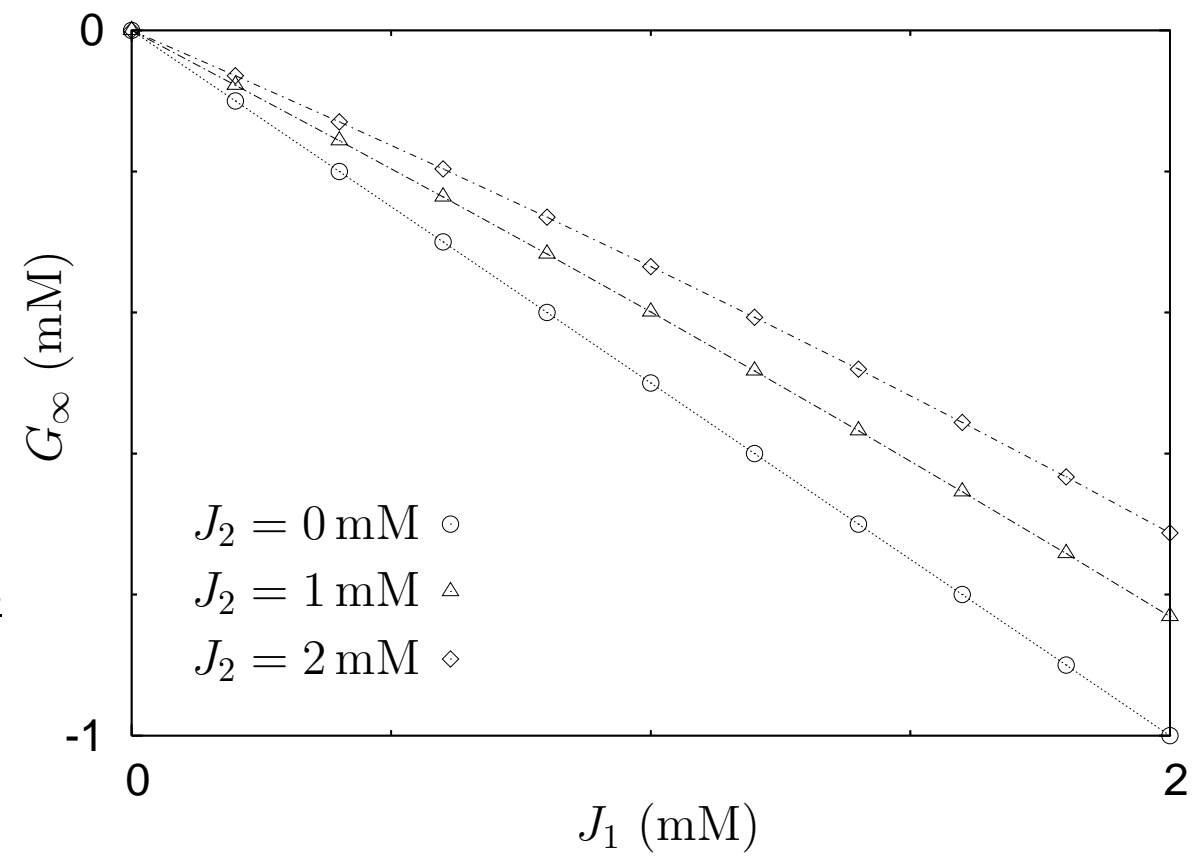

Figure 2: 


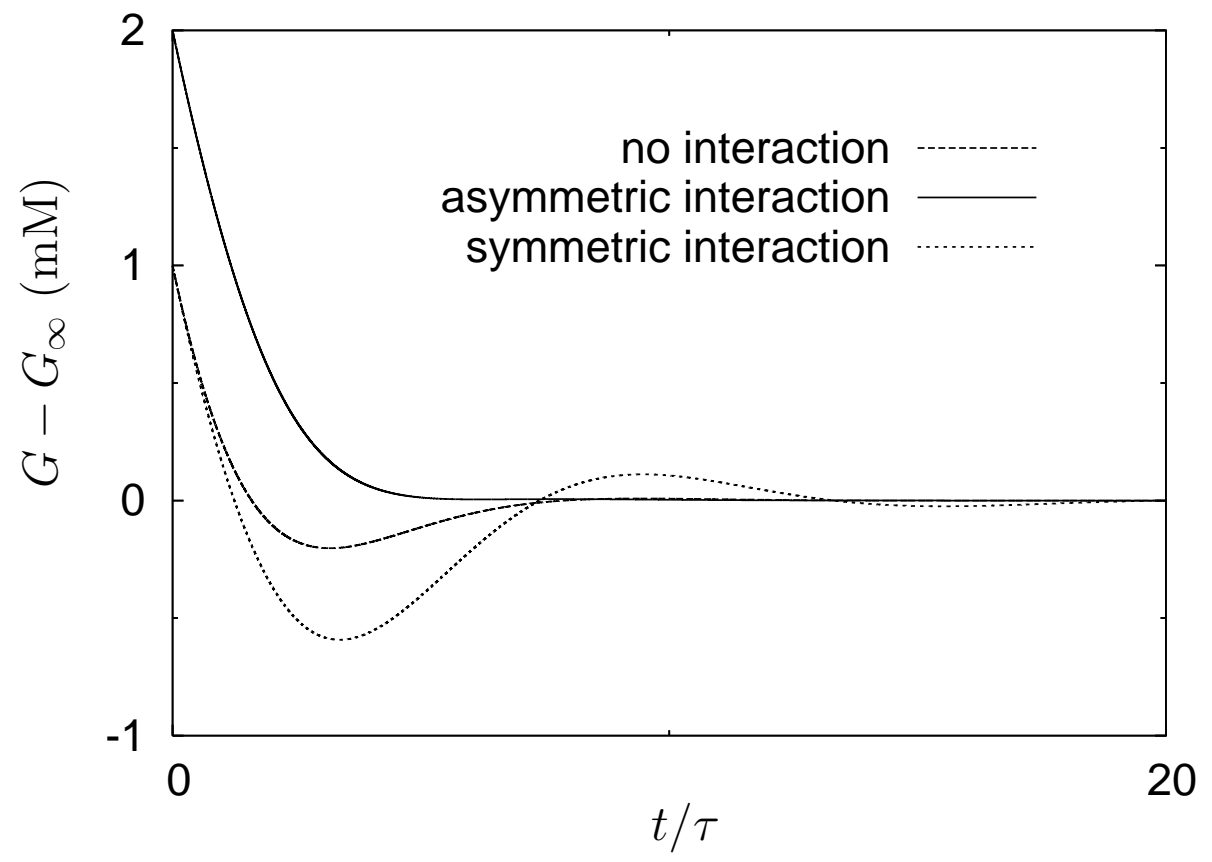

Figure 3: 


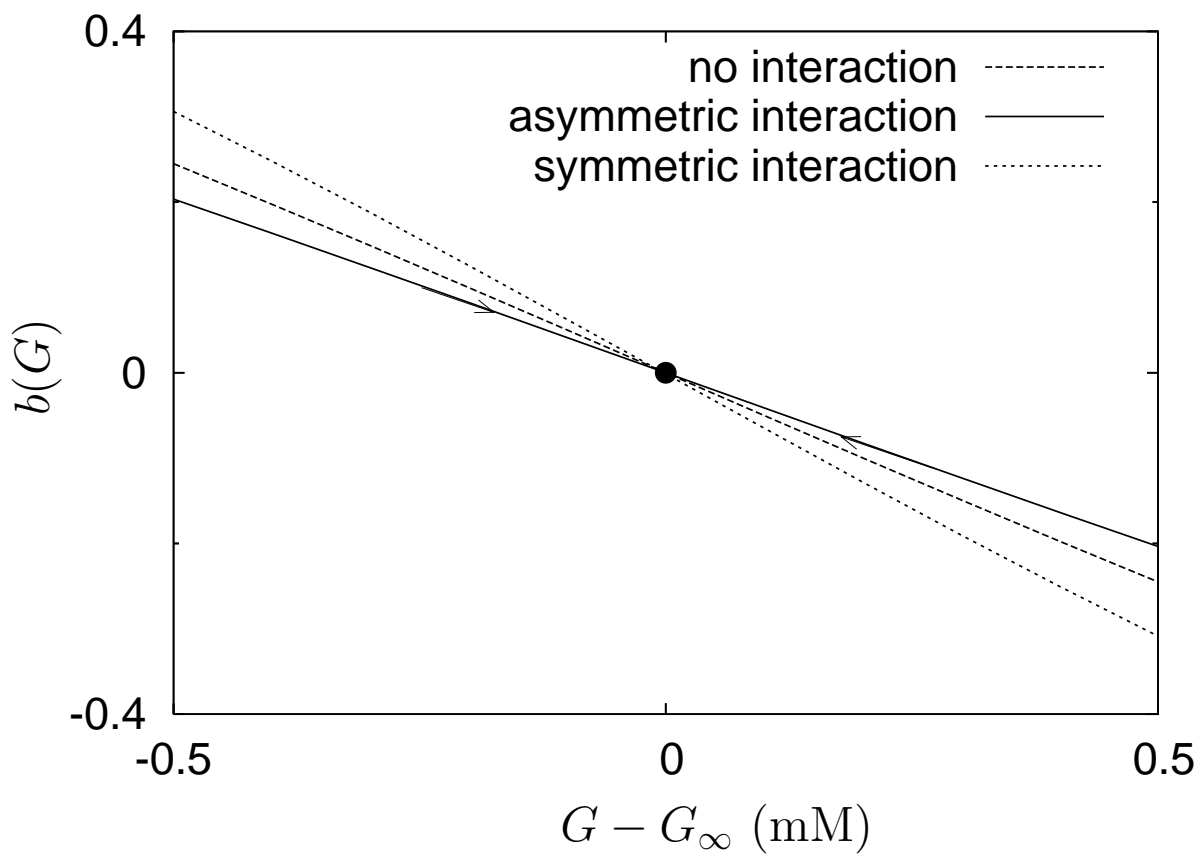

Figure 4: 


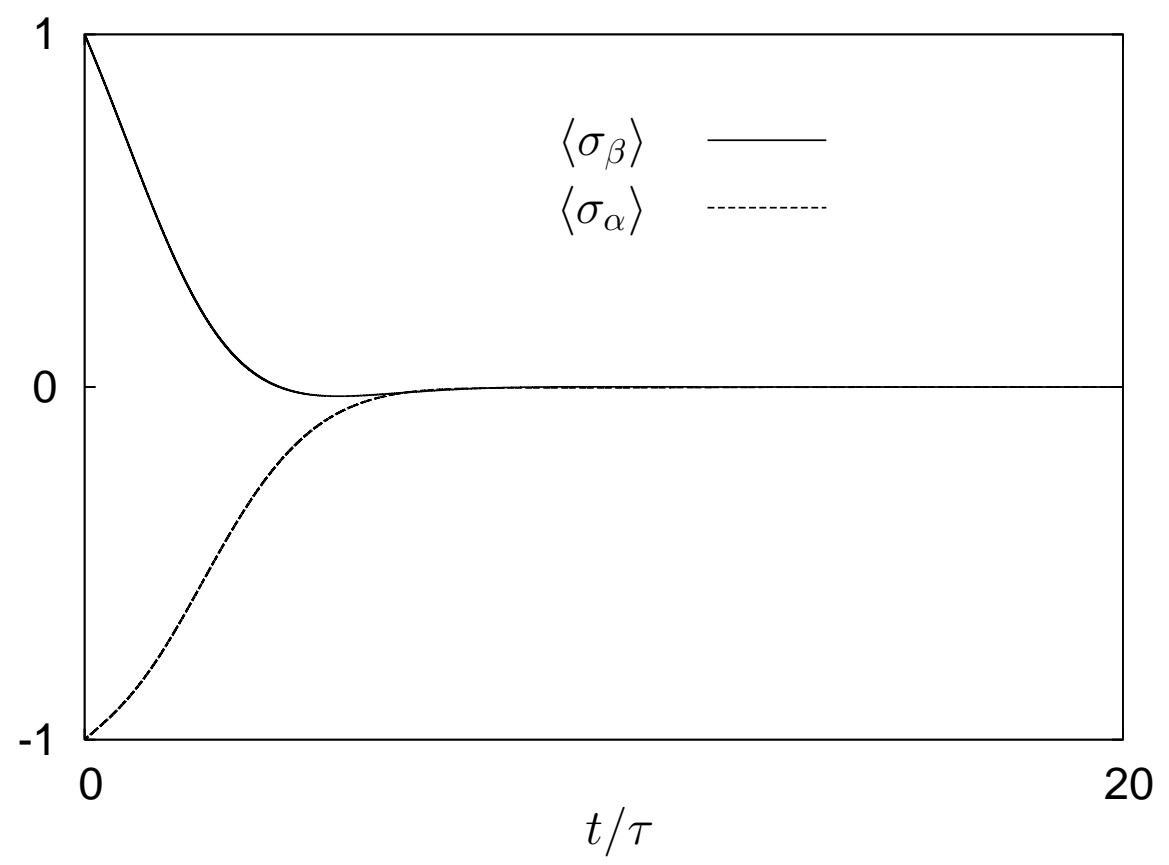

(a)

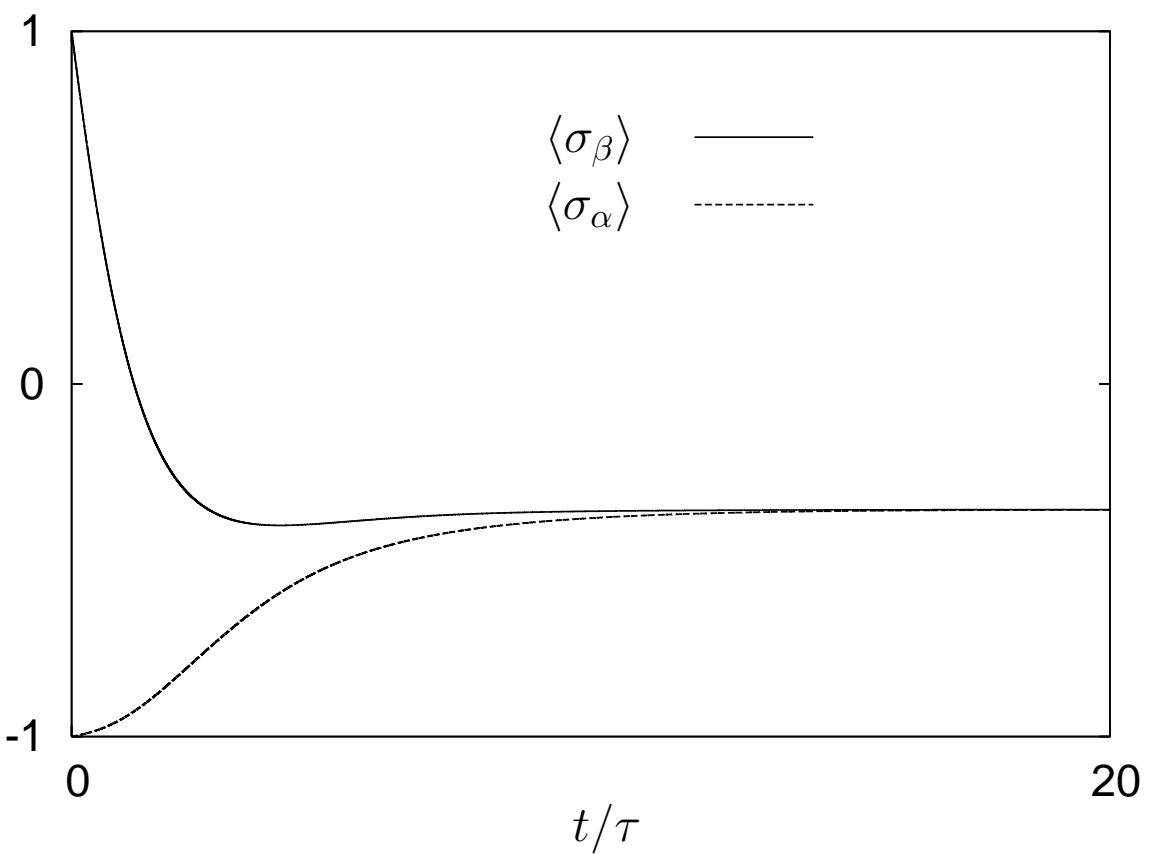

(b)

Figure 5:

38 


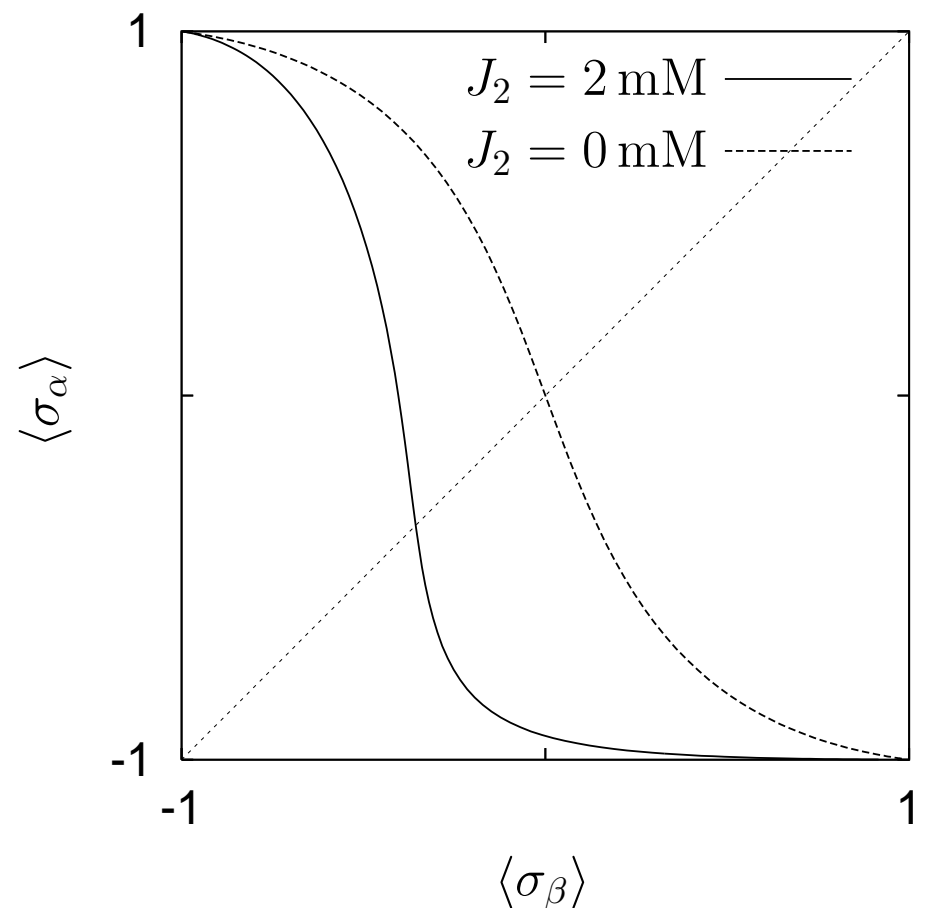

Figure 6: 


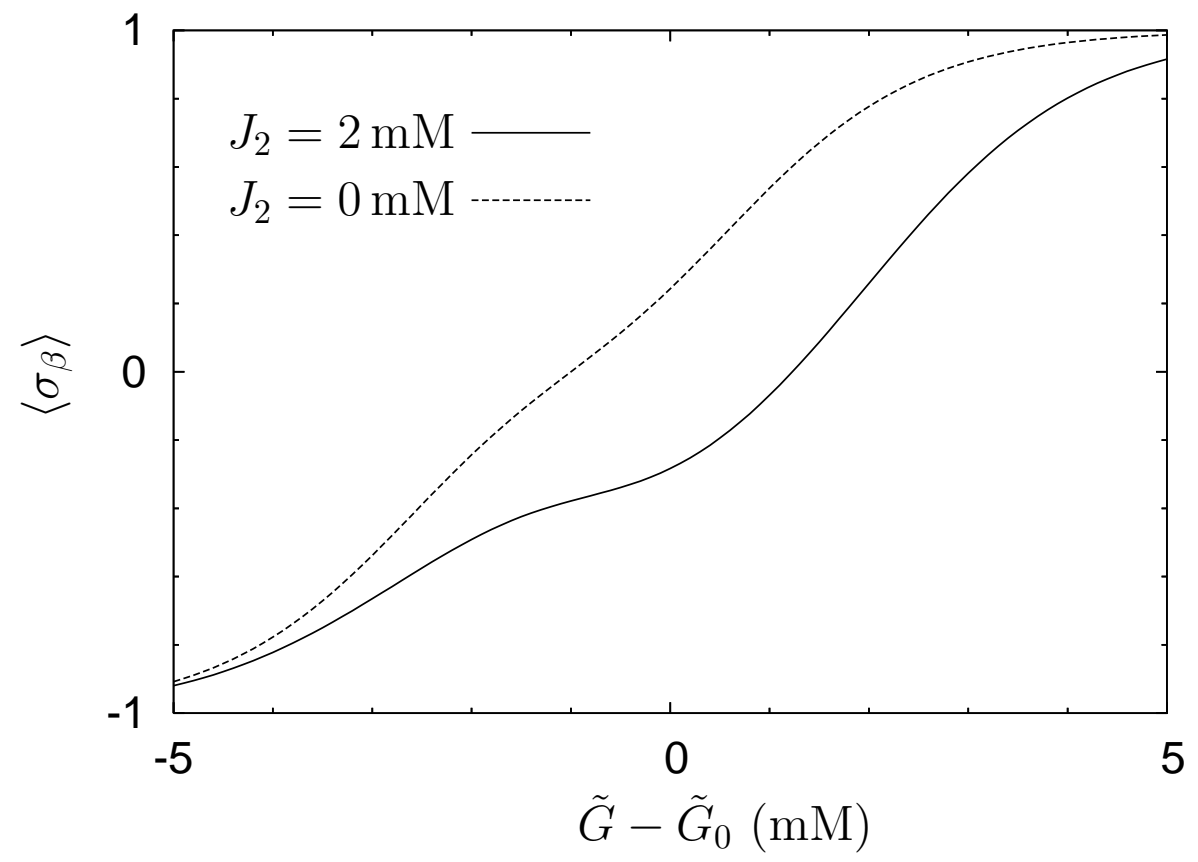

Figure 7: 